\title{
Tetraalkylammonium Fluorosilicates as Precursors for Electrochemical Deposition of Silicon Coatings. Synthesis and Thermal Stability
}

\author{
Oleksandr Gudymenko*, Volodymyr Glushakov and Oleg Boiko \\ Vernadsky Institute of General and Inorganic Chemistry, NAS of Ukraine, Kiev 03142, Ukraine
}

\begin{abstract}
Several TAAFS (tetraalkylammonium hexafluorosilicates) with different cations were synthesized. Their thermal properties were studied showing that obtained complexes are stable enough to be suitable for electrochemical deposition of silicon coatings under temperatures at least up to $200^{\circ} \mathrm{C}$.
\end{abstract}

Key words: TAAFS, electrochemical deposition, Silicon coatings, synthesis, thermal stability.

\section{Introduction}

Currently, there is strong interest in the use of cationic and anionic organic complexes for the production of films and coating of metals and nonmetals at relatively low temperatures (between $10^{\circ} \mathrm{C}$ and $\left.150-200{ }^{\circ} \mathrm{C}\right)[1,2]$.

TAAFS (tetraalkylammonium hexafluorosilicates) can also be precursors for silicon films. In Refs. [3, 4], unsuccessful attempts are described of coatings electrodeposition from TAAFS containing organic solvents. It is probable to obtain them from the low-temperature molten mixtures of TAAFS with organic cations fluorides and other salts.

The present article is the first part of the work devoted to discovery of electrochemical methods of silicon coatings deposition from low-temperature ion-organic melts. To this end, we have synthesized a series of complexes mentioned below, have studied their structure by XRD (X-ray diffraction), IR (infrared radiation) and NMR (nuclear magnetic resonance) spectroscopy methods; their thermal properties were also studied by DTA/DSC (differential thermal analysis/differential scanning calorimetry) method.

\footnotetext{
${ }^{*}$ Corresponding author: Oleksandr Gudymenko, leading engineer, research field: low-temperature ion-organic melts electrochemistry. E-mail: gudymenko@email.ua.
}

\section{Experimental Sections}

Synthesis was carried out as follows:

1. Through exchange reactions in tetraalkylammonium halide and ammonium hexafluorosilicate mixture;

2. Through reaction of the corresponding quaternary ammonium base and hexafluorosilicate acid in equimolar ratio.

Starting materials (tetraalkylammonium halides) were prepared by reactions of the corresponding tertiary amines with alkyl halides in acetonitrile, isopropyl alcohol, and mixtures thereof. Quaternary ammonium bases obtained in the form of their aqueous solutions by interactions of the corresponding quaternary tetraalkylammonium halides with wet silver oxide. Concentrations of the bases obtained were determined by titration.

2.1 Ion Exchange between Tetraalkylammonium Halide and Ammonium Hexafluorosilicate

Into a reactor equipped with a magnetic stirrer, thermometer, and reflux condenser, absolute acetonitrile, ammonium hexafluorosilicate and tetraalkylammonium chloride were placed, respectively. The reactor was placed into a 
thermostatic bath and held at a temperature $70-80{ }^{\circ} \mathrm{C}$ for 4-10 h.

$$
\begin{gathered}
\mathrm{R}_{1} \mathrm{R}_{2} \mathrm{R}_{3} \mathrm{R}_{4} \mathrm{NCl}+\left(\mathrm{NH}_{4}\right)_{2} \mathrm{SiF}_{6} \rightarrow \\
\mathrm{R}_{1} \mathrm{R}_{2} \mathrm{R}_{3} \mathrm{R}_{4} \mathrm{NSiF}_{6}+2 \mathrm{NH}_{4} \mathrm{Cl}
\end{gathered}
$$

After cooling to room temperature, the mixture was filtered and purified by chromatography with silica gel column. The solvent was eliminated under reduced pressure and a temperature of $50-70{ }^{\circ} \mathrm{C}$. The residue was treated with absolute benzene, the product was filtered and dried in vacuo $\left(10^{-2}\right.$ Torr) at a temperature $70-80{ }^{\circ} \mathrm{C}$.

\subsection{Reaction of Quaternary Ammonium Base with Hexafluorosilicate Acid}

Interaction between the corresponding ammonium base and the hexaflourosilicate acid was carried out in an aqueous medium at a temperature of $0-10{ }^{\circ} \mathrm{C}$.

$$
\mathrm{R}_{1} \mathrm{R}_{2} \mathrm{R}_{3} \mathrm{R}_{4} \mathrm{NOH}+\mathrm{H}_{2} \mathrm{SiF}_{6} \rightarrow \mathrm{R}_{1} \mathrm{R}_{2} \mathrm{R}_{3} \mathrm{R}_{4} \mathrm{NSiF}_{6}+\mathrm{H}_{2} \mathrm{O}
$$

Into the beaker equipped with a magnetic stirrer and a thermometer, an aqueous solution of fluorosilicate acid was poured, and an aqueous solution of suitable tetraalkylammonium base was added dropwise with vigorous stirring. Process temperature was $5-10{ }^{\circ} \mathrm{C}$. The solution was evaporated under $2 \mathrm{~mm} \mathrm{Hg}$ and $20{ }^{\circ} \mathrm{C}$. To the residue, acetonitrile was added, and the resulting solution was passed through a column filled with the calcined $\left(350-400{ }^{\circ} \mathrm{C}\right)$ neutral alumina. The solvent was removed under reduced pressure. To the residue, benzene was added, crystalline product was filtered and dried in vacuo $\left(10^{-2}\right.$ Torr $)$ at $70-80{ }^{\circ} \mathrm{C}$.

Three crystalline TAAFS were synthesized and studied as having the following structures: $\left(\mathrm{Me}_{2} \mathrm{Et}_{2} \mathrm{~N}\right)_{2} \mathrm{SiF}_{6} ;\left(\mathrm{Me}_{3} \mathrm{PrN}\right)_{2} \mathrm{SiF}_{6} ;\left(\mathrm{MeEt}_{3} \mathrm{~N}\right)_{2} \mathrm{SiF}_{6}$.

\section{Results and Discussion}

\subsection{Obtained TAAFS NMR Spectra}

The structure of these complexes was studied using ${ }^{1} \mathrm{H},{ }^{19} \mathrm{~F}$, and ${ }^{29} \mathrm{Si}$ NMR spectra recorded with Bruker 400 NMR spectrometer.

Proton spectra of the obtained compounds confirm the structures of their respective cations:
$\left(\mathrm{Me}_{3} \mathrm{iPrN}\right)_{2} \mathrm{SiF}_{6},{ }^{1} \mathrm{H}$ NMR $\left(\left(\mathrm{CD}_{3}\right)_{2} \mathrm{~S}=\mathrm{O}\right) \sigma 1.25(\mathrm{~d} 1, \mathrm{~J}=$ $6.0 \mathrm{~Hz}, 6 \mathrm{H}), 3.01(\mathrm{~s}, 9 \mathrm{H}), 3.77(\mathrm{~m}, \mathrm{~J}=6.0 \mathrm{~Hz}, 1 \mathrm{H})$; $\left(\mathrm{Me}_{2} \mathrm{Et}_{2} \mathrm{~N}\right)_{2} \mathrm{SiF}_{6},{ }^{1} \mathrm{H}$ NMR $\left(\left(\mathrm{CD}_{3}\right)_{2} \mathrm{~S}=\mathrm{O}\right) \sigma 1.18(\mathrm{t}, \mathrm{J}=$ $7.2 \mathrm{~Hz}, 6 \mathrm{H}) 2.97(\mathrm{~s}, 6 \mathrm{H}) 3.51(\mathrm{dd}, \mathrm{J}=7.2 \mathrm{~Hz}, 1 \mathrm{H})$; $\left(\mathrm{MeEt}_{3} \mathrm{~N}\right)_{2} \mathrm{SiF}_{6},{ }^{1} \mathrm{H}$ NMR $\left(\left(\mathrm{CD}_{3}\right)_{2} \mathrm{~S}=\mathrm{O}\right) \sigma 1.17(9 \mathrm{H})$ $2.91(3 \mathrm{H}) 3.3(6 \mathrm{H})$. NMR spectra of ${ }^{29} \mathrm{Si}$ have hyperfine structure (septet) as a result of the splitting of ${ }^{29} \mathrm{Si}$ with six equivalent fluorine atoms which confirms the structure of the complex anion $\mathrm{SiF}_{6}{ }^{2-}$. $\left(\mathrm{Me}_{3} \mathrm{PPrN}\right)_{2} \mathrm{SiF}_{6},\left(\mathrm{Me}_{2} \mathrm{Et}_{2} \mathrm{~N}\right)_{2} \mathrm{SiF}_{6},\left(\mathrm{MeEt}_{3} \mathrm{~N}\right)_{2} \mathrm{SiF}_{6},{ }^{29} \mathrm{Si}$ $\operatorname{NMR}\left(\left(\mathrm{CD}_{3}\right)_{2} \mathrm{~S}=\mathrm{O}\right) \sigma-183(\mathrm{~m}, \mathrm{~J}=112 \mathrm{~Hz}, 1 \mathrm{Si}) .{ }^{19} \mathrm{~F}$ NMR spectra indicate the presence of magnetically equivalent nuclei which is consistent with the structure of the complex anion $\mathrm{SiF}_{6}{ }^{2-}:\left(\mathrm{Me}_{3} \mathrm{i}-\mathrm{PrN}\right)_{2} \mathrm{SiF}_{6}$, ${ }^{19} \mathrm{~F} \quad \mathrm{NMR} \quad\left(\left(\mathrm{CD}_{3}\right)_{2} \mathrm{~S}=\mathrm{O}\right) \quad \sigma \quad-119.0 \quad(\mathrm{~s}, \quad 6 \mathrm{~F}) ;$ $\left(\mathrm{Me}_{2} \mathrm{Et}_{2} \mathrm{~N}\right)_{2} \mathrm{SiF}_{6},{ }^{19} \mathrm{~F}$ NMR $\left(\left(\mathrm{CD}_{3}\right)_{2} \mathrm{~S}=\mathrm{O}\right) \sigma-119.2(\mathrm{~s}$, $6 \mathrm{~F}) ;\left(\mathrm{MeEt}_{3} \mathrm{~N}\right)_{2} \mathrm{SiF}_{6},{ }^{19} \mathrm{~F}$ NMR $\left(\left(\mathrm{CD}_{3}\right)_{2} \mathrm{~S}=\mathrm{O}\right) \sigma-119.6$ $(\mathrm{s}, 6 \mathrm{~F})$.

\subsection{Obtained TAAFS IR Spectra}

Investigation of the obtained compounds structure was also performed by IR spectroscopy method using the UR-10 spectrometer.

Main IR spectra peaks (740-745 $\mathrm{cm}^{-1}$ and 470-475 $\mathrm{cm}^{-1}$ ) show the complete identity of the absorption bands for the three complexes obtained: anionic component corresponds to vibrations of the $\mathrm{SiF}_{6}{ }^{2-}$ anion.

Vibrations within the range $800-1800 \mathrm{~cm}^{-1}$ refer to the structure of the quaternary ammonium cation.

Thus, the obtained structures are corresponding to the compound with $\mathrm{SiF}_{6}$-like coordination.

\subsection{Obtained TAAFS XRD Study}

XRD analysis data of the synthesized fluorosilicate organic salt complexes have shown the formation of crystalline compounds belonging to the cubic system.

However, in our case, "degree of crystallinity" of hexafluorosilicate complexes increases in the following order of cations: dimethyldiethyl- < triethylmethyl- $<$ trimethylisopropyl-. 

Silicon Coatings. Synthesis and Thermal Stability

Lattice parameter for trimethylisopropyl derivative has the value $\mathrm{a}=9.61 \pm 0.03 \AA$. It should be noted that ammonium fluorosilicate can also form a cubic structure with the lattice parameter $\mathrm{a}=8.397 \AA$. This value of the lattice parameter is higher than that of ammonium fluorosilicate and much less then that for $\mathrm{NbF}_{6}$-containing triethylisopropylammonium complex $(\mathrm{a}=15.05 \pm 0.09 \AA)$.

\subsection{Obtained TAAFS Thermal Properties}

The study of the obtained fluorosilicates thermal properties was performed using the thermal analyzer STA 449 F1 Jupiter (Netzsch, Germany).

Temperatures of the beginning of thermal decomposition of the studied complexes were close to each other ( 270-280 ${ }^{\circ} \mathrm{C}$, Fig. 1) which means that energies of the cation-anion ionic bonds are practically identical and do not depend on (or differ only slightly with) the structure of the cation.

The process of thermal decomposition of the obtained complexes appears to be represented by the following scheme, typical for inorganic complexes of the $\mathrm{NH}_{4}^{+}, \mathrm{Li}^{+}, \mathrm{Na}^{+}, \mathrm{K}^{+}$) cations:

$$
\left(\mathrm{R}_{1} \mathrm{R}_{2} \mathrm{R}_{3} \mathrm{R}_{4} \mathrm{~N}\right)_{2} \mathrm{SiF}_{6} \rightarrow 2 \mathrm{R}_{1} \mathrm{R}_{2} \mathrm{R}_{3} \mathrm{R}_{4} \mathrm{NF}+\mathrm{SiF}_{4} \uparrow
$$

The accumulation of quaternary simple fluoride during thermal decomposition is indirectly confirmed by the formation of solidified melt after the thermal analysis (Figs. 2 and 3). Calculated loss of mass in Fig. 1 at $100-140{ }^{\circ} \mathrm{C}$ was consistent with dehydration of monohydrate followed by reactions of products of thermal hydrolysis. DSC peaks at Fig. 3 are probably caused by minor phase transitions.

Thus, the initial complex composition change during thermal decomposition leads to the formation of the binary system "tetraalkylammonium fluoride tetraalkylammonium fluorosilicate" which obviously results in the formation of lower temperature melts. Similar properties were published earlier for inorganic alkali metals fluorosilicates.

In general, the fluorosilicate complexes studied show sufficiently high thermal stability even within inorganic compounds series which decomposition temperatures are as follows: $\left(\mathrm{NH}_{4}\right)_{2} \mathrm{SiF}_{6}-175{ }^{\circ} \mathrm{C}$, $\mathrm{Li}_{2} \mathrm{SiF}_{6}-450{ }^{\circ} \mathrm{C}, \mathrm{Na}_{2} \mathrm{SiF}_{6}-650{ }^{\circ} \mathrm{C}, \mathrm{K}_{2} \mathrm{SiF}_{6}-790{ }^{\circ} \mathrm{C}$.

\section{Conclusions}

Thus, the use of such background melts to produce silicon coatings at temperatures at least up to $200{ }^{\circ} \mathrm{C}$ is fully justifiable by their respective thermal stability.

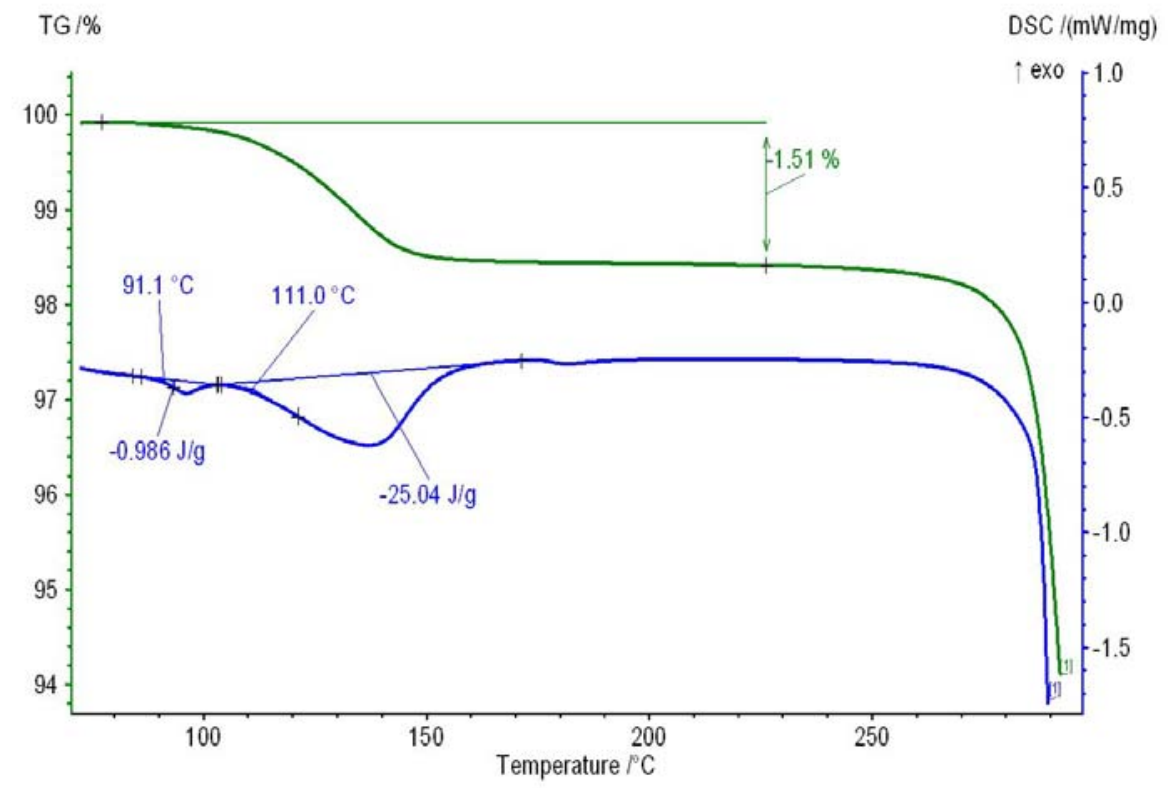

Fig. 1 TG (thermogravimetric analysis)/DSC results for $\left(\mathrm{Me}_{3} \mathrm{iPrN}\right)_{2} \mathrm{SiF}_{6}$. 


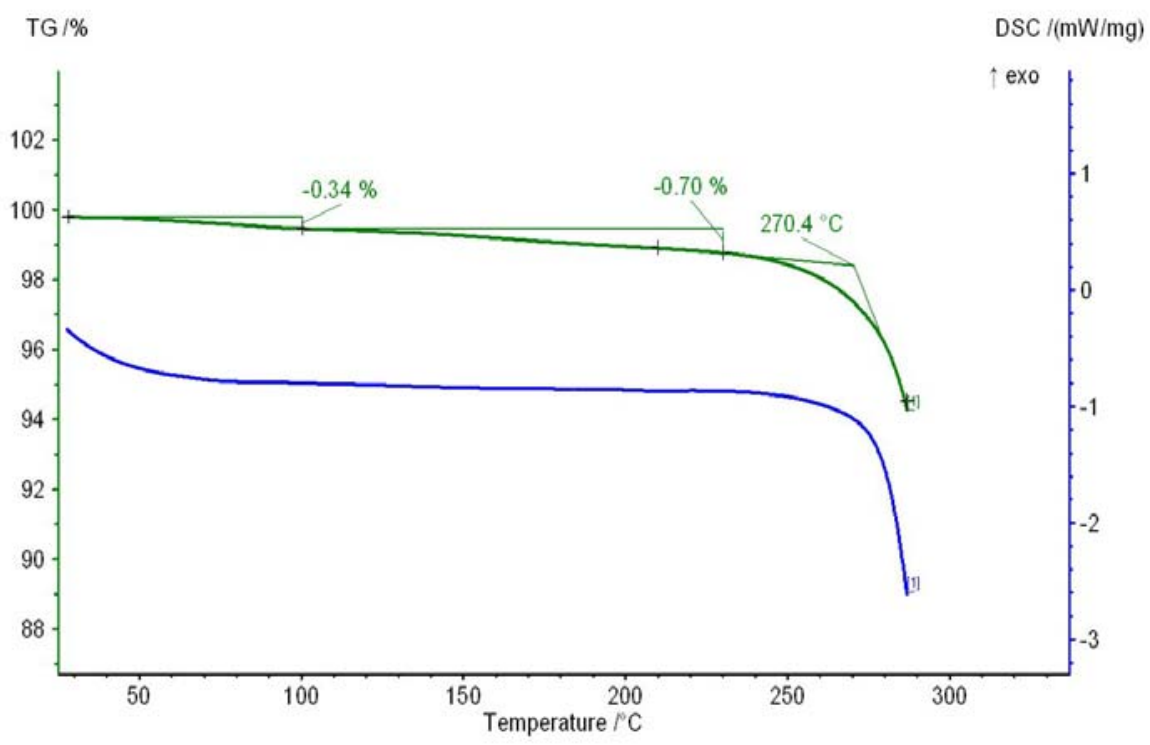

Fig. 2 TG/DSC results for $\left(\mathrm{Me}_{2} \mathrm{Et}_{2} \mathrm{~N}\right)_{2} \mathrm{SiF}_{6}$.

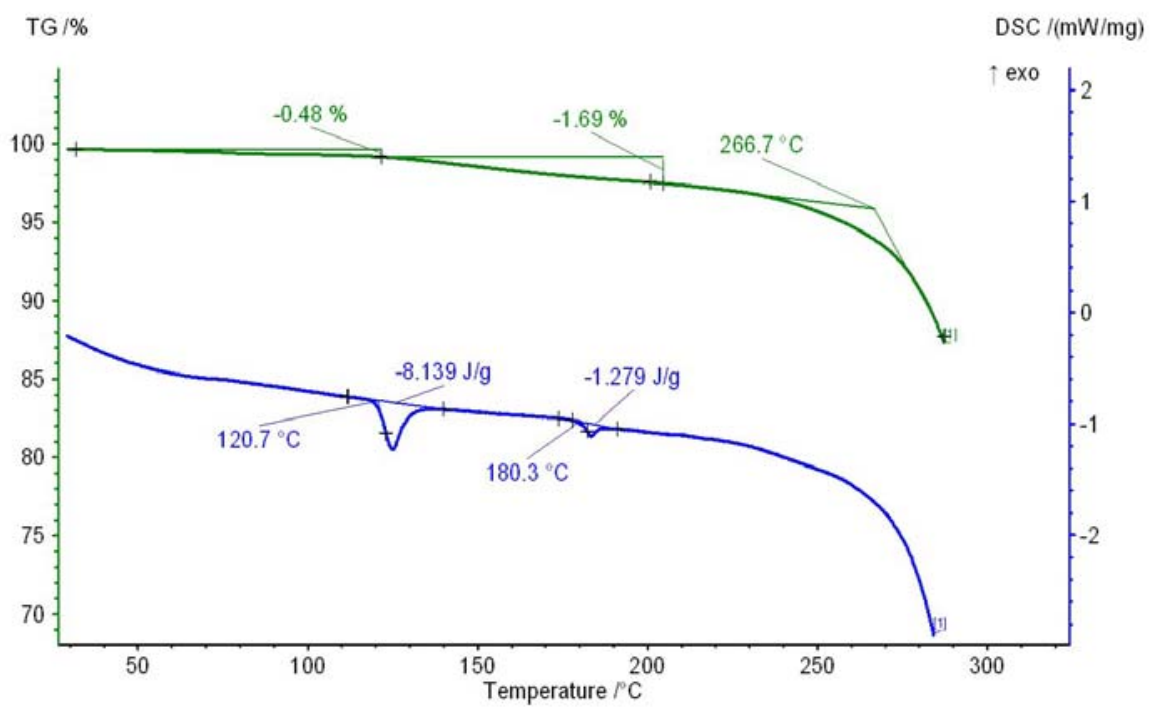

Fig. 3 TG/DSC results for $\left(\mathrm{MeEt}_{3} \mathrm{~N}\right)_{2} \mathrm{SiF}_{6}$.

\section{References}

[1] Andriyko, Y., Andriiko, A., Babushkina, O., and Nauer, G. 2010. "Electrochemistry of $\mathrm{TiF}_{4}$ in 1-butyl-2,3-dimethylimidazolium Tetrafluoroborate." Electrochimica Acta 55: 1081-9.

[2] Pulletikurthi, G., Lahiri, A., Carstens, T., Borisenko, N., Zein El Abedin, S., and Endres, F. 2013. "Electrodeposition of Silicon from Three Different Ionic Liquids: Possible Influence of the Anion on the Deposition Process." J. Solid State Electrochem. 17: 2823-32.

[3] Miller, E. 2000. "Electrodepositon of Silicon using
Hexafluorosilicate in Formamide and Dimethyl Formamide." Accessed Oct. 2, 2015. https://www.sanjuancollege.edu/documents/MathSci/CH EM/S00\%20Electrodepositon\%20of\%20Silicon\%20usin g\%20Hexafluorosilicate\%20in\%20Formamide\%20and\% 20Dimethyl\%20Formamide.pdf.

[4] Miller, E. 2002. "Electrochemical Deposition of Silicon using Tetra-Alkyl Ammonium Hexafluorosilicate Salts." $\begin{array}{llll}\text { Accessed } & \text { Oct. } & 2015 .\end{array}$ https://www.sanjuancollege.edu/documents/MathSci/CH EM/S02\%20Electrodeposition\%20of\%20Silicon\%20usin g\%20TetraAlkylAmmonium\%20Hexafluorosilicate\%20S alts.pdf. 